\title{
Black garlic: transformation effects, characterization and consumer purchase intention
}

\author{
Rita de Cássia Mirela Resende Nassur ${ }^{*}$, \\ Eduardo Valério de Barros Vilas Boas², \\ Francisco Vilela Resende ${ }^{3}$ \\ 'Bahia State University, Juazeiro, BA, Brazi \\ ${ }^{2}$ Federal University of Lavras, Lavras, MG, Brazil \\ ${ }^{3}$ Embrapa Vegetables, Brasília, DF, Brazil \\ *Corresponding author, e-mail: ritarnassur@hotmail.com
}

\begin{abstract}
Black garlic is produced from chemical and biochemical reactions when the fresh garlic bulb is submitted to specific temperature and moisture conditions. The aim of this study was to evaluate quality and nutritional changes on bulbs before and after the transformation in black garlic, presenting the new product for the consumer, evaluating the purchase intention. Commercial garlic bulbs cv. Amarante were obtained and transformed in black garlic. The color, proximate composition (moisture, crude lipid, crude protein, crude fiber, ash and nitrogen-free extract), total sugars, total phenolics content and antioxidant activity were evaluated on fresh and black garlic bulbs. The transformation of garlic in black garlic resulted in an increase on crude lipid, crude protein, total sugars, antioxidant activity and total phenolic content. A multivariate analysis was performed and the characteristics of nutritional interest were positively related to the black garlic samples and a completely separation of the products before and after processing can be observed, affirming the physical, chemical, nutritional and sensory attributes difference. Only $20 \%$ of the surveyed consumers affirmed that they already knew the product and $55 \%$ classified the product after visual evaluation between "liked slightly" and "liked very much", with $62 \%$ of purchase intention by the interviewed consumers.
\end{abstract}

Keywords: Allium sativum, antioxidant activity, chemical composition, consumer acceptance

\section{Introduction}

Garlic has played an important role in cooking as a condiment and food throughout the human history. For over 3000 years, this vegetable has been consumed as food or used as a medicine in Asian countries (Queiroz et al., 2009). Nevertheless, black garlic has been produced recently and it is not yet well-known by consumers, especially in the west side of the world.

The black garlic is produced by chemical and biochemical reactions that occur in the bulb when it is submitted to specific temperature and humidity conditions. No additives or other substances are used oradded in the transformation of garlic to black garlic, which consists of a simple fermentation of the common vegetable in controlled temperature and humidity. Black garlic flavor is unique and distinctive (sweet), with balsamic notes, sugar cane molasses or plumblack, with the advantage that this consumption does not cause undesirable bad breath after consumption. This fact has been reported as a result from the destruction of some compounds during the thermal treatment (Fante \& Noreña, 2012)

Black garlic has been named as the "ingredient of the moment" at gastronomic area and it has aroused the curiosity and the taste of consumers. It is a golden skin material with dark 
colored bulbs, differing from the garlic and any other raw material. Recently, it has been used in haute cuisine as an ingredient in savory or sweet dishes, with great acceptance, especially when combined with pasta. In Brazil, their production in a larger scale and even craft production is still limited by the lack of specific methodology, product disclosure and technical knowledge.

It is possible to find reports about black garlic with pharmacological, nutritional and antioxidant properties (Wang et al, 2012; Gardner et al, 2007; Lee et al, 2009) and the influence on temperature on black garlic quality characteristics (Zhang et al., 2015), mainly in eastern countries, where the product is better known by scientists and consumers. Studies about the quality characteristics and nutritional value of black garlic produced in Brazil as well as changes that can occur during its transformation are still scarce. On this way, the aim of this study was to evaluate quality and nutritional changes on garlic bulbs before and after the transformation in black garlic, presenting the new product for the consumers and evaluating their purchase intention.

\section{Material and Methods}

Commercial bulbs of cv. Amarante garlic were obtained and transformed in black garlic. The cultivar Amarante was selected due to its higher number of bulblets and a higher mass per bulb, resulting in higher production of the final product. The bulbs were selected according to homogeneity of mass and size (mean of 40 grams per bulb and diameter above $40 \mathrm{~mm}$ ), avoiding those visibly injured and diseased at Postharvest Laboratory at the Federal University of Lavras (UFLA), Brazil. Three replicates of 500 grams each were separated for the analysis before transformation of the garlic in black garlic. Bulbs for black garlic production (three replicates of 500 grams each) were placed in an oven set at $67^{\circ} \mathrm{C}$ and $90 \% \mathrm{RH} \pm 2.1$ for 22 days. The relative humidity $(\mathrm{RH})$ was achieved with a water container placed into the oven and replaced when necessary to maintain the RH and the time was set according to the product characteristics (golden skin and black bulbs). After obtaining the black garlic, each portion was separated in three parts, resulting in nine repetitions after drying. Nine repetitions of the raw garlic was also separated.

The following analyses were performed on fresh material (white garlic) and on black garlic (after transformation) with the objective of results comparison, in order to verify the effects of transformation on garlic characteristics.

The garlic color was evaluated in nine replicates per bulb, for the nine repetitions per treatment (white and black garlic) with a Minolta CR-400 colorimeter with a CIE L*a*b* determination. The $L^{*}$ coordinate represents how darker is the sample, with values from 0 (totally black) to 100 (totally white) and it is normally used to indicate browning; the $a^{*}$ coordinate can vary from -80 to +100 where the extremes correspond to green and red, respectively; the $b^{*}$ coordinate indicates the color from blue to yellow and can vary from -50 (totally blue) to +70 (totally yellow). This variables are used to calculate the cylindrical coordinates of color named Hue angle ( ${ }^{\circ} \mathrm{Hue}$ ) that indicates the color in a $360^{\circ}$ angle and Chroma (C*) that represents color purity. In this study, the results will be expressed in L*, Chroma and Hue values.

The proximate composition of garlic and black garlic was performed according to the methodology proposed by the AOAC (2012). The moisture was determined by the gravimetric method with heat, based on the sample mass loss when submitted to $105^{\circ} \mathrm{C}$, the crude lipid was quantified by the soxhlet gravimetric method based on the mass loss of the material submitted to ether extraction. The crude protein was determined by Kjeldahl (†otal nitrogen). To determine the fixed mineral residue, the sample was incinerated in a muffle furnace at $550^{\circ} \mathrm{C}$. The determination of dietary crude fiber was performed according to the techniques proposed by AOAC (2012) and the nitrogen free extract (NNE) was determined subtracting the values obtained in previous analyses of $100 \mathrm{~g}$ of the product, in fresh mass.

The $\mathrm{pH}$ of the black and raw garlic were determined by a potentiometric method according to AOAC (2012) methodology. The total sugar content was evaluated by spectrophotometry at $620 \mathrm{~nm}$, according to 
antrona method (Dische, 1962), and the results were given as grams of glucose per $100 \mathrm{~g}$ of the garlic tissue.

The total phenolic content was determined according to Folin-Ciocalteau method, which involves the phenolic compounds with concomitant formation of a blue complex whose intensity increases linearly at $760 \mathrm{~nm}$, as described by Rumbaoa et al., (2009). The aqueous and ethanolic extracts of bulbs were dissolved in methanol in order to achieve a concentration of $0.5 \mathrm{mg}$.solids. $\mathrm{mL}^{-1}$. The total phenolic compounds level for each extract were then quantified according to the standard curve prepared with gallic acid, and the results were expressed as gallic acid equivalents (GAE).

The antioxidant activity was measure by two different methods, in order to perform a better information about the black and white garlic antioxidant activity, since each method measure different forms of the radical scavenging. For the DPPH method, the determination was based on the free DPPH (2,2-Diphenyl-1-picrylhidrazil) radical scavenging, that led to an absorbance increase at $515 \mathrm{~nm}$ (Rufino et al., 2007a) with previous tests for raw and black garlic and results expressed in percentage of free radical scavenge (\%FRS), according to control. For the ABTS method, the ABTS assay was performed according to a method developed by Rufino et al. (2007b). ABTS radical cations were produced by the reaction of $7 \mathrm{mM}$ ABTS stock solution with $145 \mathrm{mM}$ potassium persulfate. The ABTS solution was diluted with ethanol until it reaches $0.70 \pm 0.02$ of absorbance at $734 \mathrm{~nm}$. After the addition of 30 $\mu \mathrm{l}$ of sample or trolox standard to $3 \mathrm{ml}$ of diluted ABTS solution, absorbances were recorded at 6 min after mixing. Ethanolic solutions with fixed trolox concentrations were used as a standard and results were expressed as $\mu \mathrm{M}$ trolox g-1 garlic.

After the transformation, the black garlic was submitted to a visual evaluation and purchase intention by consumers. The black garlic was placed on a white tray where black garlic samples of bulbs and bulblets, peeled and unpeeled were presented to consumers as well as the hedonic scale with answers to the questions asked. The survey was conducted in cities of the South of Minas Gerais state, with
60 garlic consumers. Product appearance was evaluated according on 9-point hedonic scale $(9=$ liked very much to 1 = disliked very much) and the purchase intention was made by visual assessment through a hedonic scale of 5 points, with the value 5 corresponding to 'certainly buy 'and 1 to 'certainly would not buy ' the product, according to Lawless and Heymann (2010).

The experiment was conducted in a completely randomized design with two treatments (fresh and black garlic), with nine repetitions each. The laboratory analysis was carried out in triplicate for each repetition. The results were submitted to variance analysis and the means were compared according to Tukey's test at $5 \%$ of probability using the software Sisvar $^{\oplus}$. For a better visualization of the results, a multivariate analysis was also performed with the aid of the XLStat ${ }^{\oplus}$ software.

\section{Results and Discussion}

The quality of a new product can be evaluated according to its nutritional compounds, its chemical, physical and physicchemical characteristics. The means for the evaluated garlic characteristics, before and after the black garlic transformation are presented in Table 1.

The $L^{*}$ coordinate indicates the lightness of the sample and it can vary from 0 to 100 . Higher the number, whiter the sample. So this variable can just inform us how black or white is the sample, and according to the results, it is possible to confirm that the garlic before transformation had a high lightness and after the transformation in black garlic, the $L^{*}$ value decreases, indicating that the product became darker. During the transformation of garlic, the development of black color is related to the temperature that will lead to non-enzymatic browning reactions. There were melanoidins forming in Maillard reaction. Color of melanoidins might be connected with the enolization of sugars and racemization of amino acids (Kim \& Lee, 2008).

When the Chroma and the Hue angle were evaluated, the black garlic samples presented lower values. Chroma presents the quality of a color's purity, intensity or saturation and lower the chroma value, more neutral is the 
Table 1 - Means for color, proximal composition, $\mathrm{pH}$, total sugars, phenolic compounds and antioxidant activity on fresh and black garlic.

\begin{tabular}{lll}
\hline Variable & Fresh garlic & Black garlic \\
\hline L* $^{*}$ & $81.57 \mathrm{a}$ & $24.55 \mathrm{~b}$ \\
Chroma & $21.26 \mathrm{a}$ & $2.67 \mathrm{~b}$ \\
Hue & $94.74 \mathrm{a}$ & $69.35 \mathrm{~b}$ \\
Moisture (\%) & $72.42 \mathrm{~b}$ & $79.42 \mathrm{a}$ \\
Lipids (\%) & $0.11 \mathrm{~b}$ & $0.43 \mathrm{a}$ \\
Fiber (\%) & $6.32 \mathrm{a}$ & $5.59 \mathrm{a}$ \\
Ash (\%) & $3.01 \mathrm{~b}$ & $3.36 \mathrm{a}$ \\
Protein (\%) & $10.62 \mathrm{~b}$ & $11.75 \mathrm{a}$ \\
Nitrogen-free extract (\%) & $7.50 \mathrm{a}$ & $0.56 \mathrm{~b}$ \\
pH & $6.14 \mathrm{a}$ & $4.61 \mathrm{~b}$ \\
Total sugars (g 100g ${ }^{-1}$ ) & $2.24 \mathrm{~b}$ & $35.29 \mathrm{a}$ \\
Total phenolics (mg EAG.100g-1) & $35.98 \mathrm{~b}$ & $52.20 \mathrm{a}$ \\
Antioxidant activity - DPPH - (\%SRL) & $10.40 \mathrm{~b}$ & $56.87 \mathrm{a}$ \\
Antioxidant activity - ABTS - $\mu \mathrm{MM} \mathrm{Trolox} \mathrm{g-1}^{-1}$ & $19.65 \mathrm{~b}$ & $31.50 \mathrm{a}$ \\
\hline Same letter for the same attribute: means are not different according to Tukey's test at 5\% of probability
\end{tabular}

color, indicating that the black garlic has a lower saturation when compared to raw garlic. The Hue angle is the common distinction between colors positioned around a color wheel and it makes sense only when evaluated with other color variables ( $L^{*}$ and Chroma). It is possible to observe that $L^{*}$ has a strong influence on the sample color, since the Hue angle did not vary too much, even with a significant statistical difference. With the global color evaluation, it is possible to notice a big change in garlic color before and after transformation.

According to Table 1, black garlic presented a higher moisture content when compared to raw/white garlic, emphasizing the presence of a high relative humidity during the adopted process. Zhang et al., (2015) observed that when the temperature increase during black garlic transformation, the product moisture content decreases and the authors affirmed that the decrease rate of moisture content was faster with the temperature increase during the transformation.

The moisture content can have a direct influence on black garlic quality. Zhang et al. (2015) during their study on the temperature effect in black garlic, demonstrated that when the black garlic moisture content achieved 35 to $40 \%$, the black garlic was drier and its elasticity was not good, and when the moisture content achieved below 35\%, the product became much harder, which is also undesirable. With a higher moisture content, the product can be more susceptible to deterioration by microorganisms, otherwise this fact was not observed in the present study and possibly an increase of $9.66 \%$ of this content may not be sufficient to the deterioration process beginning.

The crude lipid content (\%) increased almost four times when the bulbs were submitted to the transformation process and it was possible to feel an oiliness characteristic on black garlic. Since the moisture content of black garlic was higher than the one on fresh garlic, it is not possible that a concentration in lipids level happened. There are no papers discussing the lipid content on black garlic and future studies should be carried out to elucidate the synthesis or changes in lipid content in black garlic, including quantitative, metabolic and qualitative analysis.

No differences on the percentage of crude fiber in the evaluated samples were 
noticed, according to statistical analysis, with the mean of the samples varying from $6.32 \%$ for fresh garlic to $5.59 \%$ for black garlic. For ash and crude protein content, black garlic presented statistically higher values. Garlic is considered a vegetable with higher mineral content. Minerals can be co-factors during vegetable biochemical reactions and their absence in human body can be related to diseases, if the food intake does not provide the necessary mineral level.

The protein level in fresh garlic is important because it is used as a substrate to Maillard reaction that occurs during black garlic transformation. Otherwise, it can be seen (Table 1) that black garlic presented higher protein amount than raw garlic, even with small difference in their content. The melanoidin pigment, formed during Maillard reaction, might be connected with racemization of amino acids (Kim and Lee, 2008). The author's initial hypothesis was that the Maillard reaction could consume amino acids and the protein level of black garlic would be lower than the same level on fresh garlic. It was not proved in the present study and new studies should be carried out to investigate protein dynamics on black garlic and during the process.

The nitrogen-free extract is concerned to carbohydrates of the food, except the fiber portion and it is composed mainly by sugars and starch. Most part of it can be digested and used as an energy source. Since the total sugar content in black garlic is higher (Table 1) when compared to fresh garlic, the nitrogen-free extract was probably used as an energy source for the sugar metabolism, justifying the difference of free-nitrogen extract between the samples (carbohydrate content on fresh garlic is 13 times higher and the sugar concentration on black garlic is almost 16 times higher).

A lower $\mathrm{pH}$ can be observed for the black garlic, which can be associated to a higher acidity. According to Liang et al., (2015) the organic acids profile is different for garlic extracts before and after processing and they affirm that is possible to observe changes on $\mathrm{pH}$ during the thermal processing. Acetic acid and succinic acid were observed for the same authors on black garlic, but the presence was not observed in fresh garlic samples, indicating that the presence of these acids can be associated to a lower $\mathrm{pH}$ on black garlic samples.

Liang et al (2015) also found a reduction on $\mathrm{pH}$ values when comparing the means for fresh and black garlic, assenting with the results of this present study, and the authors attributed the reduction to a decrease in allicin content, resulting in a final product with a 'smoother' taste, since this compound is responsible for the strong garlic odor. Zhang et al. (2015) reported that an increase in acidity on garlic samples submitted to heat can partly be associated with browning substances formed and is reported that the formation of carboxylic acids substances can lead to an increase in acidity.

The total sugars content is about $60 \%$ higher on black garlic samples, when comparing to fresh garlic, and comparing the same materials, an increase in 15.75 times was observed for the total sugars content evaluated by spectroscopy. According to Zhang et al. (2015), polysaccharide in garlic is degraded to reducing sugar, but these sugars can be consumed during Maillard reaction. The same authors observed that, when submitted to temperatures about $70^{\circ} \mathrm{C}$, the garlic can form reducing sugars faster than its consumption rate and that this temperature in the process provided a better processed product, with an abundant sweet flavor.

Garlic is a vegetable rich in a number of phenolic compounds (Bozin et al., 2008) and it is suggested that phenolic compounds content can increase about 4 to 10 times when the fresh garlic is processed to obtain the black garlic (Kim et al., 2013; Choi et al., 2008). In the present study, an increase in $45 \%$ was observed for the total phenolics content when the garlic was submitted to the transformation, ranging from

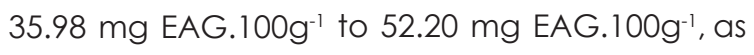
can be observed on Table 1. These results are in accordance to Zhen et al., (2015), that observed an increase in the phenolics content when the black garlic was obtained.

According to Choi et al. (2008), an increase of total phenols content improves total antioxidant capacity of black garlic. The Folin Ciocalteu method for determination of phenolic compounds is similar to antioxidant activity 
determination; therefore, the values should at least partially express antioxidant activity (Prior et al., 2005). Tsai et al. (2005) demonstrated that a significant correlation $(P<0.05)$ existed between antioxidant activity and total phenolics content.

It is important the evaluation of the antioxidant activity by different chemical assays, since it validated the problems of using a single one-dimensional method to evaluate this activity and multifunctional food and biological antioxidants. In the present study, we evaluated the garlic antioxidant activity by two different methodologies that, together, can explain part of the garlic antioxidant capacity. For the DPPH method, the antioxidant capacity increased about 5 times during the processing of the garlic and for the ABTS methodology, an increase of the antioxidant capacity from 16.65 to $31.50 \mu \mathrm{M}$ Trolox $\mathrm{g}^{-1}$ was also observed (Table 1). The trend observed here for results of the two chemical assays for antioxidant activity determination was also observed in previous vegetable studies (Strail et al., 2006). Lee et al. (2009) also observed a higher antioxidant activity on black garlic and suggested the insertion on diabetics diets, without problems with the disease indexes.

Previous studies confirmed that the phenolic is an important component of garlic. Queiroz et al. (2014) studied ready-to-eat garlic products and found that there was a significant decrease in the total phenolics content due to storage halfway to the expiration date. This relationship was confirmed with processed vegetables in Somman and Siwarungon (2015) study, that observed the fresh garlic with 1.76 of phenolic content increase to 19.48 at 10 days after processing and also observed antioxidant activity from the DPPH method of $25.53 \%$ for the fresh garlic. The total antioxidant activity of vegetables and fruits has been extensively studied using various chemical-based assays including 2.2-diphenyl-picrylhydrazyl (DPPH) (Lu et al., 2011).

Rahmam et al. (2012) studied garlic and concluded that the vegetable has a strong antioxidant activity, evaluating the product by the DPPH scavenging method and suggested that the product can be a source of antioxidant, even fresh or processed. Gardner et al (2007), studying the black garlic, affirmed that it is more powerful for therapeutic and antioxidant properties when compared to fresh garlic.

In addition, according to the literature, increments in the polyphenols and flavonoids content (Kim et al., 2012) were observed in black garlic after the process. Other reports confirmed the potential health benefits of black garlic by chemical analysis (Kim et al., 2012; Sato et al., 2006).

According to the results of the chemical and nutritional properties of the fresh and black garlic, it is possible to conclude that the black garlic is a processed food obtained by subjecting the fresh garlic to higher temperatures and relative humidity, resulting in chemical reactions, such as the Maillard reaction, which change the composition of the garlic (Liang et al., 2015), being possible to obtain a whole new product, with a completely different and interesting characteristics.

For a better visualization of the results, a multivariate analysis was performed with the chemical analysis for the fresh and black garlic, which can be observed on Figure 1. Each point for the fresh or black garlic is a mean of three evaluations for each analysis. The samples before and after processing were clearly separated and the most interesting characteristics for human nutrition are positively correlated to the black garlic samples, such as fiber, antioxidant capacities, etc, being possible to conclude that the composition of the product was completely changed and a new product for the consumer, that have no chemical, physical and sensorial relation with the fresh garlic.

After processing, the antioxidant capacity, total soluble solids and total sugars, fiber and protein contents increase its content, due to the compounds changes, discussed before. Since the luminosity $\left(L^{*}\right)$ range from 0 to 100 and higher the $L^{*}$ value, brighter the sample, it is clear that this variable is positively correlated with fresh garlic, and negatively correlated to black garlic samples.

The purchase intention evaluation was performed in three municipalities of the South of the Minas Gerais State, Brazil with a total of 60 consumers, being 44 women and 16 men with 
Biplot (eixos F1 e F2: $94.25 \%$ )

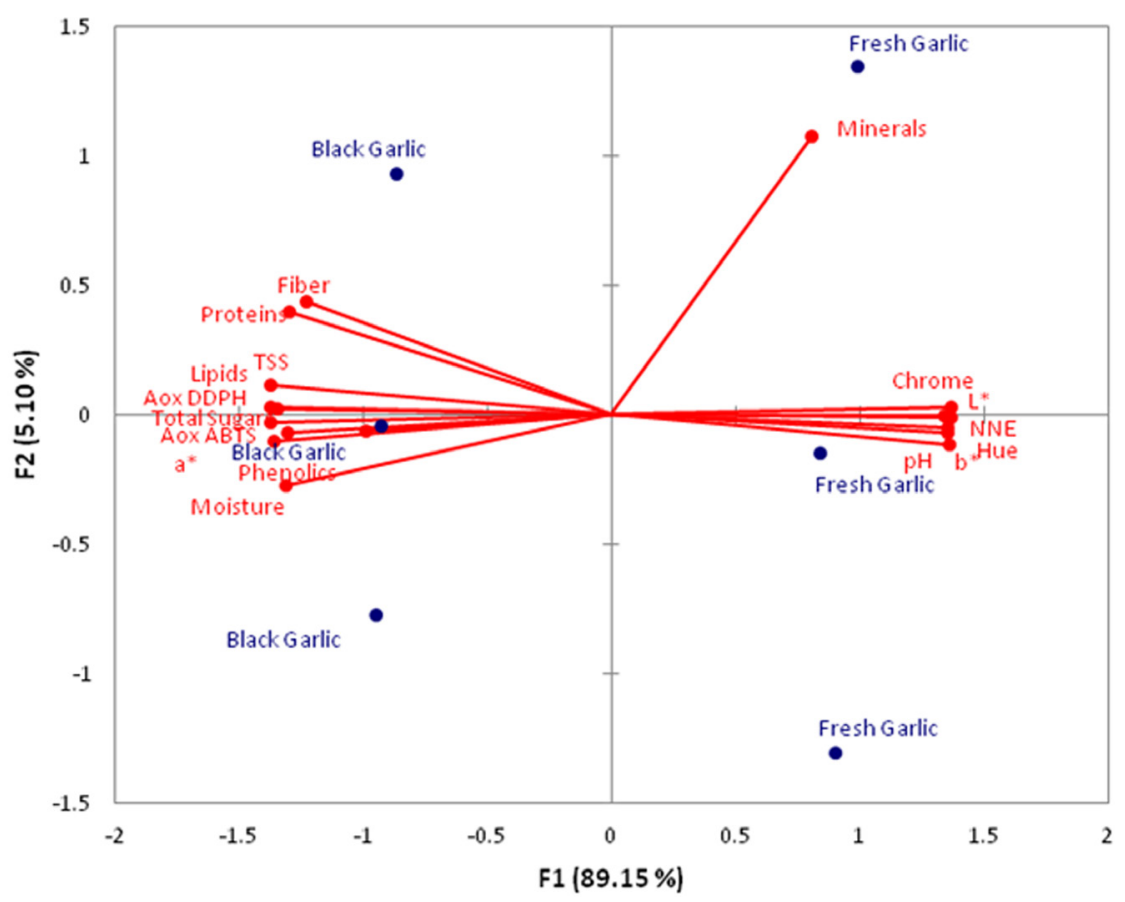

Figure 1: Principal component analysis for the garlic before (fresh garlic) and after thermal processing (black garlic) according to the performed analysis.

ages varying from 15 to 70 years old. According to the results, only $20 \%$ of the interviewed consumers knew the product and $55 \%$ of the consumers evaluated the product from 'like slightly' to 'liked very much'. For the purchase intention, the notes ranged from 'would not buy' to 'would buy' and about $62 \%$ of the consumers presented some intention to buy the product, but only $28 \%$ affirmed that would 'certainly buy' the black garlic. Thirty-eight (38\%) of the consumers provided answers from 'I am not sure if I would buy' from 'certainly not buy'. It is possible to conclude that the black garlic is not well-known by consumers and this fact could explain the low means of consumers that would 'certainly buy' the product. New sensory tests with flavor, aroma, taste and appearance evaluations should be carried out and are necessary in order to obtain a better profile of the black garlic consumers.

\section{Conclusions}

With the processing of the fresh garlic to obtain the black garlic the chemical and physical composition of the product was completely changed, with statistical increase for the contents of lipids, minerals, total soluble solids, total sugars, phenolic content and antioxidant activity, evaluated by two different methodologies.

The black garlic is a product that about $20 \%$ of the interviewed consumers already known, but most of them confirmed their intention to buy.

\section{References}

AOAC - Association of Official Analytical Chemistry. 2012. Official methods of analysis. 19th ed. Gaithersburg. 3000p.

Bozin, B., Mimica-Dukic, N., Samojlik, I., Goran, A., Igic, R. 2008. Phenolics as antioxidants in garlic (Allium sativum L. Alliaceae). Food Chemistry 111 : 925-929.

Choi, D.J., Lee SJ. Kang MJ. Cho HS. Sung NJ and Shin JH. 2008. Physicochemical characteristics of black garlic (Allium sativum L.). Journal of Korean Society of Food Science and Nutrition 37: 465-471.

Fante, L., Noreña, C. P. Z. 2012. Enzyme inactivation kinetics and colour changes in Garlic (Allium sativum L.) blanched under different conditions. Journal of Food Engineering 108 (3): 436-443.

Gardner, C. D., Chatterjee, L. M., Carlson, J. J. 2007. The effect of a garlic preparation on plasma lipid levels in moderately hypercholesterolemic adults. Atherosclerosis 154 (1): 213-220.

Kharazi, P. 2005. GC and mass-spectrometric comparison of organo sulfur compounds in two varieties of Iranian garlic. Phosphorus, Sulfur, 
Silicon and Related Elements 180 : 67-75.

Kim, J.S., Lee, Y.S. 2008. Effect of reaction $\mathrm{pH}$ on enolization and racemization reactions of glucose and fructose on heating with amino acid enantiomers and formation of melanoidins as result of the Maillard reaction. Food Chemistry 108: $582-592$

Kim, J., Nam, S., Rico, C., Kang. M. 2012. A comparative study on the antioxidative and antiallergic activities of fresh and aged black garlic extracts. International Journal of Food Science and Technology 47: 1176-1182.

Kim, J. S., Kang, O. J., Gweon, O. C. 2013. Comparison of phenolic acids and flavonoids in black garlic at different thermal processing steps. Journal of Functional Foods 5: 80-86.

Lawless, H. T., \& Heymann, H. 2010. Sensory evaluation of food: principles and practices. Springer Science \& Business Media. 598p.

Lee. Y., Gweon. O., Seo. Y., Im. J., Kang. M., Kim. M., Kim. J. 2009. Antioxidant effect of garlic and aged black garlic in animal model of type 2 diabetes mellitus. Nutrition Research Practices 3: 156-161.

Liang. T., Wei. F., Lu. Y., Kodani. Y., Nakada. M., Miyakawa. T., Tanokura, M. 2015. Comprehensive NMR Analysis of Compositional Changes of Black Garlic during Thermal Processing. Journal of Agriculture and Food Chemistry 63: 683-691.

Lu, X., Ross, C. F., Powers, J. R., Aston, D. E., Rasco, B. A. 2011 . Determination of Total Phenolic Content and Antioxidant Activity of Garlic (Allium sativum) and Elephant Garlic (Allium ampeloprasum) by Attenuated Total Reflectance-Fourier Transformed Infrared Spectroscopy. Journal of agricultural and food chemistry: 59 (10): 52155221.

Prior. R. L., WU. X., Schaich. K. 2005. Standard methods for the determination of antioxidant capacity and phenolics in foods and dietary supplements. Journal of Agriculture and Food Chemistry 53: 4290-4302.

Queiroz, Y. S., Ishimoto, E. Y., Bastos, D. H., Sampaio, G. R., Torres, E. A. 2009. Garlic (Allium sativum L.) and ready-to-eat garlic products: In vitro antioxidant activity. Food chemistry 115 (1): 371-374.

Queiroz, Y. S., Antunes, P. B., Vicente, S. J., Sampaio, G. R., Shibao, J., Bastos, D. H., Torres, E. A. D. S. 2014. Bioactive compounds, in vitro antioxidant capacity and Maillard reaction products of raw, boiled and fried garlic (Allium sativum L.). International Journal of Food Science and Technology 49 (5): 1308-1314.
Rahman, M. M., Fazlic, V., Saad, N. W. 2012. Antioxidant properties of raw garlic (Allium sativum) extract. International Food Research Journal 19 (2): 589-591.

Rufino, M. S. M., Alves, R. E., Brito, E. S., Morais, S. M., Sampaio, C. G., Pérez-Jimenez, J., Sauracalixto, F. D. 2007a. Metodologia Científica: Determinação da Atividade Antioxidante total em frutas pela captura do radical livre DPPH. EMBRAPA: Comunicado técnico 127 - on line. Fortaleza, Brasil.

Rufino, M. S. M., Alves, R. E., Brito, E. S., Morais, S. M., Sampaio, C. G., Pérez-Jimenez, J., Sauracalixto, F. D. 2007b. Metodologia Científica: Determinação da Atividade Antioxidante total em frutas pela captura do radical livre ABTS+. EMBRAPA: Comunicado técnico 128 - on line. Fortaleza, Brasil.

Rumbaoa, R.G.O., Fernandes, F. A.N., Aves, R.E., Brito, E.S. 2009. Phenolic content and antioxidant capacity of Philipine sweet potato varieties. Food Chemistry 113: 1133-1138.

Sato. E., Kohno. M., Hamano. H., Niwano. Y. 2006. Increased antioxidative potency of garlic by spontaneous short-term fermentation. Plant and Food Human Nutrition 61: 157-160.

Somman, A., Siwarungson, N. 2015. Comparison of antioxidant activity and tyrosinase inhibition in fresh and processed white radish. garlic and ginger. Journal of Food Measurement and Characterization 1: 1-6.

Strail. P., Klejdus. B., Kuban. V. 2006. Determination of total content of phenolics compounds and their antioxidant activity in vegetables Evaluation of spectrophotometric methods. Journal of Agriculture and Food Chemistry 54: 607-616.

Tsai, T.H., Tsai, P.J., Ho, S.C. 2005. Antioxidant and anti-inflammatory activities of several commonly used spices. Journal of Food Science 70: 93-97.

Wang. X., Jiao. F., Wang. Q., Wang. J., Yang. K., Hu. R., Liu. H., Wang. H., Wang. Y. 2012. Aged black garlic extract induces inhibition of gastric cancer cell growth in vitro and in vivo. Molecular Medical Reports 5: 66-72.

Zhang, Z., Lei, M., Liu, R., Gao, Y., Xu, M., Zhang, M. 2015. Evaluation of alliin, saccharide contents and antioxidant activities of black garlic during thermal processing. Journal of Food Biochemistry 39 (1): 39-47. 